CARAKA : Indonesian Journal of Communications, vol. 1(2), 2020, 80-90

\title{
Play Victim dalam Lirik Lagu-Lagu Taylor Swift
}

\author{
https://doi.org/10.25008/caraka.v1i2.48 \\ DEDDY MUHARMAN \\ NINDITA KARTIKA \\ MEGA MERCIA \\ Institut Komunikasi dan Bisnis LSPR Jakarta - Indonesia
}

\begin{abstract}
The role of play victim is very common in everyday life. In almost all aspects of life there will be people who play this role. play victim is where someone manipulates a situation and positions himself in that state. Taylor swift, one of the world's celebrities has been accused of playing the victim to her former lovers. This is shown through the lyrics of the song which was composed not long after he had a broken heart and seemed to be aimed at all of his former lovers. The songs include shake it off, you belong with me, blank space, love story and I knew you were trouble. The purpose of this research is to find out whether Taylor Swift plays the victim through his lyrics and how fans react after knowing what her idol has done. This study uses a qualitative method. Data obtained by conducting in-depth interviews with Taylor Swift fans and secondary data with observations through magazine articles, websites and news. The conclusions obtained from this research show that implicitly, Taylor Swift plays the victim and feels as a victim as a result of the treatment of her former lover and also the victim of ridicule and criticism from haters. But he doesn't really care about what other people say because he thinks he is unable to regulate other people's opinions or words.

Key words: Play Victim, Symbolic Interaction, Communication, Taylor Swift's song
\end{abstract}

\section{ABSTRAK}

Taylor Swift, dituding melakukan playing victim dan berperan sebagai korban dari mantan kekasihnya. Hal ini terlihat dari lirik lagu yang dibuatnya setelah ia patah hati dan seakan ditujukan untuk mantan kekasihnya. Lagu tersebut antara lain Shake It Off, You Belong with Me, Blank Space, Love Story, dan I Knew You Were Trouble. Tujuan penelitian ini untuk mengetahui bagaimana Taylor Swift melakukan Play Victim melalui lagunya; mengetahui apakah penggemar Taylor Swift menyadari sang idola melakukan Play Victim dan apakah mereka tetap menjadi penggemar Taylor Swift setelah tahu apa yang dilakukan olehnya? Penelitian ini menggunakan metode kualitatif. Data primer diperoleh melalui wawancara mendalam dengan fans Taylor Swift dan data sekunder dari artikel majalah, website dan berita. Hasil penelitian menunjukkan, secara implisit Taylor Swift melakukan playing victim dan menjadi korban dari mantan kekasihnya. Dia juga merasa dirinya adalah korban dari ejekan dan cacian para haters-nya. Meski begitu, Taylor tidak peduli dengan apa yang dikatakan oleh orang lain. Menurutnya, tidak ada yang bisa mengatur opini atau perkataan orang lain.

Kata kunci: Play Victim, Interaksi Simbolik, Komunikasi, Lagu Taylor Swift

Dedi Muharman's email: deddy.m@lspr.edu

Para penulis menyatakan tidak mempunyai konflik kepentingan dalam penelitian dan penerbitan publikasi ini.

Copyright (C) 2020 (Dedi Muharman, Nindita Kartika, Mega Mercia).

Licensed under the Creative Commons Attribution-NonCommercial-ShareAlike 4.0 (CC BY-SA 4.0)

Available at http://caraka.web.id

Submitted: 19 November 2020, Revised: 10 December 2020, Accepted: 26 December 2020 


\section{PENDAHULUAN}

Peran sebagai play victim sangat popular dan sering terjadi di kehidupan sehari-hari. Tidak hanya dalam dunia pergaulan saja, sikap play victim pun ditemukan terjadi di dunia politik hingga dunia hiburan. Swahn dan Svahn menjelaskan play victim merupakan suatu penyakit, cacat, kehilangan, atau berbagai macam kesalahan orang. Victim atau korban adalah kondisi seseorang menyalahkan orang lain atas apa yang terjadi dan tidak bertanggung jawab karena menyebabkan tersebut. Pelaku play victim menunjukan sikap ini agar mereka mendapatkan belas kasihan dan simpati sehingga mereka bisa melimpahkan tanggung jawab atas situasi yang terjadi kepada orang lain (Swahn, \& Svahn, 2008).

Salah satu kasus play victim yang terjadi di dunia politik ditulis oleh Pendekar Sakaw dalam artikelnya Taktik Play Victim Mantan Presiden dan di muat dalam Kompasiana. Pendekar Sakaw menyebutkan mantan Presiden RI dari partai Mercy sangat memahami bagaimana mental rakyat Indonesia sehingga dia mengandalkan taktik play victim dalam segala aktivitas politiknya.

Beliau memposisikan dirinya sebagai korban yang lemah dan menarasikan bagaimana sedihnya diberhentikan dari posisi menteri dan dihujat oleh banyak orang untuk mendapatkan belas kasihan dan simpati dari orang banyak (Sakaw, 2017). Kasus play victim lainnya yang ramai diberitakan di media massa adalah kasus yang menjerat mantan Gubernur DKI Jakarta Basuki Tjahja Purnama atau Ahok. Beliau menjadi tersangka dengan tuduhan penistaan agama.

Artikel berjudul Operasi Playing Victim Pasca-Ahok Tersangka yang ditulis oleh Iswandi Syahputra pada harian Republika menyebutkan ada tiga fenomena terkait playing victim yang dimainkan oleh Ahok. Pertama, peperangan tagar dari kelompok pro dan kontra Ahok yang dimenangkan oleh kelompok pro Ahok, sehingga menjadi viral dan pesan yang disampaikan dapat menimbulkan kenikmatan semu atau realitas palsu.

Fenomena kedua adalah membangun citra Ahok sebagai korban, sehingga dapat meraih simpati yang luas. Fenomena ketiga adalah menghadapkan Ahok dengan Habib Rizieq, sehingga diperkirakan dapat memecah konsentrasi umat muslim, dan mendapatkan simpati tambahan dari penganut muslim yang kontra dengan Habib Rizieq (Operasi Playing Victim Pasca-Ahok Tersangka, 2017).

Kasus play victim yang ramai dibicarakan di dunia hiburan salah satunya melibatkan penyanyi Taylor Swift. Dikutip dari website IMDB.com, pemilik nama asli Taylor Alison Swift merupakan penyanyi dan pencipta lagu asal negara Amerika. la menjadi artis termuda dalam sejarah yang memenangkan Grammy Award untuk nominasi Album of The Year (Taylor Swift Biography n.d).

Selain terkenal karena lagu-lagunya, Taylor juga terkenal karena kebiasaannya yang sering berganti-ganti pasangan. Joe Jonas, Taylor Lautner, John Mayer, Jake Gyllenhaal, Conor Kennedy, Harry Styles, dan Calvin Harris adalah sederet artis yang pernah menjalin hubungan dengan Taylor. Hampir sebagian besar lirik lagu yang ditulis oleh Taylor Swift terinspirasi dari kisah cintanya dengan mantan kekasihnya (Apriliani, 2016).

Lagu-lagu Taylor yang easy listening dengan lirik yang menggambarkan perasaan jatuh cinta, galau, patah hati mampu membawa pendengarnya larut terbawa perasaan. Salah satu lagu yang diciptakan Taylor menceritan korban patah hati yang merasakan kesedihan teramat dalam akibat ditinggalkan pasangannya. Banyak orang menduga, lirik lagu ini menggambarkan kisah cinta Taylor dengan salah satu pasangannya yang kandas. Tetapi, ada juga yang menganggap Taylor Swift melakukan play victim untuk mendapatkan perhatian dan keuntungan dari lagu-lagu yang diciptakannya. 


\section{KERANGKA TEORI}

Pada dasarnya, komunikasi merupakan kegiatan utama yang dilakukan seluruh individu. West \& Turner menyebut komunikasi merupakan proses sosial individu-individu menggunakan simbol-simbol untuk menciptakan dan meninterpretasikan makna dalam lingkungan mereka. Komunikasi memiliki dua jenis dalam bentuk penyampaiannya, yakni verbal, meliputi lisan dan tulisan, non-verbal meliputi mimik wajah dan bahasa tubuh (West \& Turner, 2018).

Setiap interaksi antarindividu melibatkan suatu pertukaran simbol, ketika kita berinteraksi dengan yang lainnya maka kita secara langsung akan mencari tahu mengenai makna apa yang dimaksudkan oleh orang lain. Oleh karena itu, dalam penelitian ini, Teori Interaksi Simbolik menjadi teori utama yang digunakan sebagai alat analisis untuk melihat bagaimana Taylor Swift mencoba menunjukkan konsep diri sebagai seorang wanita yang sering menjadi korban, khususnya dalam hubungan asmara dan hubungannya dengan para haters dan penggemar.

Interaksi simbolik, mempusatkan pada interaksi antarindividu, dan bagaimana hal ini digunakan untuk memahami apa yang orang lain katakan dan lakukan kepada kita sebagai individu. Interaksi simbolik didasarkan pada ide-ide mengenai diri dan hubungannya dengan masyarakat. Menurut Ralph LaRossa dan Donald C.Reitzes, ada tiga asumsi yang mendasari Teori Interaksi Simbolik yaitu; pentingnya makna bagi perilaku manusia, pentingnya konsep mengenai diri, dan hubungan antara individu dengan masyarakat (West \& Turner, 2018).

Dari ketiga asumsi tersebut, teori Interaksi Simbolik berpegang, individu membentuk makna melalui proses komunikasi. Karena tujuan interaksi dari teori ini adalah untuk menciptakan makna yang sama, makna juga dimodifikasi melalui proses interpretasi. Hal ini penting karena tanpa makna yang sama berkomunikasi akan menjadi sulit atau bahkan tidak mungkin. Oleh karena itu, penting adanya komunikasi yang jelas antar sesama individu agar terciptanya makna yang sesuai.

Asumsi selanjutnya dalam Interaksi Simbolik yaitu berfokus pada pentingnya Konsep Diri (Self Concept), atau seperangkat perspektif yang relatif stabil yang dipercaya orang mengenai dirinya sendiri. Seseorang mengembangkan konsep diri melalui interaksinya dengan orang lain, dan konsep diri memberikan motif yang penting untuk perilaku seseorang. Asumsi yang terakhir berkaitan dengan hubungan antara kebebasan individu dan batasan sosial. Dalam hal ini diterangkan, orang dan kelompok dipengaruhi oleh proses sosial dan budaya, sehingga perilaku seseorang atau kelompok orang dibatasi oleh norma-norma yang ada. Begitupun mengenai struktur sosial, hal ini dihasilkan melalui interaksi sosial (West \& Turner, 2018).

Selain ketiga asumsi tersebut, George H. Mead dalam bukunya Mind, Self, and Society, menggambarkan bagaimana pikiran individu dan diri individu berkembang melalui proses sosial, hal ini terkait dan mendukung dimana dalam interaksi simbolik terdapat tiga konsep utama:

Mind/Pemikiran. Menurut Mead, Pikiran merupakan kemampuan untuk menggunakan simbol yang mempunyai makna sosial yang sama, dan manusia harus mengembangkan pikirannya melalui interaksi dengan orang lain. Proses ini memiliki dua jenis simbol yaitu Bahasa yang merupakan simbol verbal dan nonverbal yang diatur dalam pola-pola untuk mengekspresikan pemikiran dan perasaan yang dimiliki bersama. Bahasa tergantung pada apa yang disebut simbol signifikan, atau simbol-simbol yang maknanya secara umum disepakati oleh banyak orang.

Terkait erat dengan konsep ini adalah apa yang didefinisikan oleh istilah pemikiran itu sendiri yang dinyatakan sebagai percakapan di dalam diri sendiri. Dalam hal ini dijelaskan 
bahwa tanpa rangsangan sosial dan interaksi dengan orang lain, orang tidak akan mampu mempunyai ataupun mempertahankan pemikirannya. Dan selanjutnya, salah satu aktivitas penting yang diselesaikan orang melalui pemikiran yaitu pengambilan peran, atau kemampuan secara simbolik untuk menempatkan dirinya sendiri dalam diri khayalan dari orang lain. Kondisi ini mensyaratkan bahwa seseorang menghentikan perspektifnya sendiri dan sebaliknya membayangkan dari perspektif orang lain. Hal ini menjelaskan perasaan kita mengenai diri dan juga memungkinkan kita untuk mengembangkan kapasitas untuk berempati dengan orang lain.

Self/Diri. Diri merupakan kemampuan untuk merefleksikan diri kita sendiri dari perspektif orang lain atau dengan kata lain membayangkan bagaimana kita dilihat oleh orang lain. Dalam hal ini, Mead menjelaskan mengenai konsep cermin diri, yaitu kemampuan kita untuk melihat diri kita sebagaimana diri kita dilihat oleh orang lain. Menurut Cooley dalam buku Wet\&Turner, ada tiga prinsip pengembangan yang dihubungkan dengan cermin diri yaitu; kita membayangkan bagaimana kita terlihat dimata orang, kita membayangkan penilaian mereka mengenai penampilan kita dan kita kita merasa tersakiti atau bangga berdasarkan perasaan pribadi ini. Sehingga kita akan belajar mengenai diri kita sendiri dari cara orang lain memperlakukan kita, memandang kita, dan memberi label pada kita. Pemberian sebuah label terhadap diri kita untuk menghasilkan pemenuhan diri dalam hal ini disebut efek Pygmalion, yaitu hidup diatas atau dibawah harapan orang lain mengenai kita.

Mengenai konsep mengenai diri, Mead menjelaskan melalui Bahasa, orang mempunyai kemampuan untuk menjadi subjek dan objek bagi dirinya sendiri. Sebagai subjek atau "saya" (I), kita bertindak sedangkan sebagai objek atau "Me", kita mengamati diri kita sendiri bertindak. I bersifat spontan, impulsive dan kreatif, sedangkan Me bersifat reflektif dan lebih peka secara social. Mead melihat diri sebagai sebuah proses yang mengintegrasikan antara I dan Me.

Society/Masyarakat. Masih dalam buku West\&Turner, Mead mendefinisikan Masyarakat sebagai jejaring hubungan sosial yang diciptakan dan direspons oleh manusia. Individu-individu terlibat dalam masyarakat melalui perilaku yang mereka pilih secara aktif dan sukarela. Sehingga, masyarakat menggambarkan keterhubungan beberapa perangkat perilaku yang terus disesuaikan oleh individu-individu. Masyarakat terdiri atas individuindividu, dan terbagi atas dua bagian penting masyarakat yang mempengaruhi pikiran dan diri. Dua bagian tersebut yaitu orang lain secara khusus atau individu-individu dalam masyarakat yang penting bagi kita, orang-orang ini biasanya adalah anggota keluarga, teman, kolega, dll. Kita melihat orang lain secara khusus tersebut untuk mendapatkan rasa penerimaan social dan rasa mengenai diri.

Selanjutnya yaitu orang lain secara umum, dimana merujuk pada cara pandang dari sebuah kelompok sosial atau budaya sebagai suatu keseluruhan. Hal tersebut diberikan oleh masyarakat kepada kita dan sikap dari orang lain secara umum adalah sikap dari keseluruhan komunitas. Orang lain secara umum memberikan kita perasaan mengenai bagaimana orang lain bereaksi kepada kita dan harapan social secara umum. Perasaan ini berpengaruh dalam mengembangkan kesadaran sosial. Dimana orang lain secara umum dapat membantu dalam menengahi konflik yang dimunculkan oleh kelompok-kelompok orang lain secara khusus yang berkonflik (West \& Turner, 2018).

Berdasarkan penjelasan mengenai teori interkasi simbolik di atas, peneliti memilih teori tersebut untuk penelitian ini dikarenakan peneliti melihat bahwa Taylor Swift mempunyai keinginan atau harapan pribadi yang ia inginkan melalui lagu-lagu yang ia ciptakan. Taylor Swift memanfaatkan momen dirinya putus cinta untuk mendapatkan inspirasi dalam menulis 
lagu sehingga dirinya meraih keuntungan dan kesuksesan dari lagu-lagunya yang disukai oleh para penggemarnya.

\section{METODOLOGI}

Dalam penelitian ini, peneliti menggunakan pendekatan kualitatif. Definisi metode kualitatif yaitu metode penelitian yang berusaha menggambarkan atau melukiskan objek yang diteliti berdasarkan fakta yang ada dilapangan.

Penelitian kualitatif adalah rangkaian proses kegiatan atau penyaringan data atau informasi yang masuk di akal tentang suatu masalah pada aspek atau bidang tertentu dalam suatu objek. Rencana kerja atau pedoman pelaksanaan penelitian ini menggunakan pendekatan kualitatif, yang pengumpulan datanya berupa pendapat, pertanyaan, konsep dan informasi yang berupa deskripsi dalam mengungkapkan permasalahan.

Data primer yang didapat dalam penelitian ini diperoleh langsung melalui wawancara kepada penggemar Taylor Swift untuk mendapatkan informasi yang mendalam mengenai tanggapan mereka terhadap Play Victim yang dilakukan oleh Tayloy Swift.

Untuk data sekunder diperoleh dari majalah, atau artikel berita. Pada intinya, data sekunder terbagi menjadi beberapa jenis, yaitu otobiografi, surat pribadi, buku atau buku harian, memorial, kliping, dokumen, data di server dan flash, data yang tersimpan di website, dll. Data sekunder ini akan berguna sebagai pendukung data primer yang dapat berfungsi sebagai pelengkap data yang tidak terjawab pada pengumpulan data primer.

Terdapat beberapa orang yang akan menjadi informan dalam penelitian ini yakni para penggemar artis Taylor Swift yang dipilih secara random sampling. Karakteristik dari informan tersebut yaitu: laki-laki atau perempuan; penggemar Taylor Swift, dan memahami lagu-lagu dan cerita hidup Taylor Swift.

Pemilihan informan menggunakan snowball sampling: peneliti menemukan satu informan melalui informan yang lain, dengan bertanya kepada seseorang yang memiliki pengetahuan tentang area atau topik tertentu dan bersedia untuk mengambil bagian dalam penelitian ini. Pada gilirannya, ia mencalonkan individu lain sebagai informan. Peneliti menggunakan sampling bola salju kaarena informasi tidak mudah diakses (Daymon \& Holloway, 2011).

\section{HASIL PENELITIAN}

Menurut Kate Martindale, play victim adalah peran yang dimainkan oleh seseorang sebagai korban untuk mendapatkan perhatian atau memanipulasi suatu keadaan (Martindale, 2016). Seseorang yang memainkan peran sebagai korban akan membuat orang di sekitarnya berusaha untuk membantu masuk dalam permainan mereka. Setiap bantuan yang diberikan kepada pelaku akan selalu dirasa kurang, sehingga mereka yang berusaha membantu merasa jenuh bahkan menjauh.

Keadaan itu akan membuat pelaku kembali mengatakan "tidak ada seorang pun yang mengerti keadaanku dan dapat membantuku". Mereka akan lebih mendramatisir keadaan. Tidak jarang mereka berakting menyakiti diri sendiri bahkan mengancam akan mengakhiri hidupnya. Dengan begini, mereka akan membuat banyak orang merasa bersalah dan mereka akan mendaptkan semakin banyak perhatian (Myler, 2017).

Salah satu selebrita yang kehidupannya sempat ramai dibicarakan adalah Taylor Swift. Selain karena prestasinya, Swift dikenal sering berganti pasangan dan berseteru dengan beberapa selebrita lain seperti Katy Perry, Kim Kardashian hingga Kanye West (Soraya, 2016).

Lirik lagu yang diciptakan oleh Taylor Swift menceritakan perasaan yang ia rasakan saat menjalin hubungan dengan para mantan kekasihnya. Dibalut dengan irama yang catchy, lagu 
ciptaan Taylor Swift meledak di pasaran dan membuat namanya semakin dikenal oleh publik. Tidak hanya satu dua kali, hampir setiap kisah cintanya kandas Taylor Swift selalu membuat lagu yang menceritakan kehidupan percintaannya. Pola berulang yang dilakukan Taylor Swift memunculkan anggapan bahwa hubungan asmara yang selama ini ia jalin hanyalah sebagai bahan untuk lagu-lagunya saja.

Drama percintaan Taylor Swift yang berulang kali gagal berhasil menyita perhatian publik. Bahkan beberapa kali Taylor Swift mengganggap dirinya adalah pihak yang tersakiti. Keadaan ini, dimanfaatkannya untuk menciptakan lagu yang diyakini ditujukan untuk mantan kekasihnya. Beberapa lagu yang diciptakan Taylor untuk mantan kekasihnya yaitu Last Kiss yang ditujukan untuk Joe Jonas, I Know You Were Trouble untuk Harry Styles dan Dear John untuk John Mayer (Soraya, 2016). Keadaan inilah yang membuat sebagian orang berfikir Taylor Swift memelintir kebenaran dan melakukan play victim.

Salah satu kisah cinta Taylor Swift yang menarik adalah hubungannya dengan personil Jonas Brother, Joe Jonas. Mereka dinilai pasangan yang romantis, sangat serasi tetapi akhirnya hubungan mereka kandas juga. Perpisahan Taylor Swift dan Joe Jonas ramai diperbincangkan setelah Taylor Swift menjadi bintang tamu dalam acara Ellen Show. Taylor bercerita Joe Jonas memutuskan hubungan mereka melalui sambungan telepon berdurasi 27 detik.

Joe Jonas melalui situs Jonas Brother mengklarifikasi cerita tersebut dan mengatakan bahwa Taylor yang memutuskan sambungan telepon tersebut. Tak lama setelahnya, Taylor Swift meluncurkan single Better Than Revenge. Kejadian ini membuat sebagian publik menilai Taylor Swift telah melakukan play victim terhadap mantan kekasihnya saat itu yaitu Joe Jonas (Romadhon, 2016).

Dikutip dari artikel Billboard.com, Taylor Swift's 40 Biggest Billboard Hot 100 Hits, lima lagu terpopuler milik Taylor Swift adalah Shake It Off, You Belong with Me, Blank Space, Love Story, dan I Knew You Were Trouble (Staff, 2017). Lagu-lagu tersebut hampir semuanya menceritakan perasaan Taylor Swift terhadap mantan kekasihnya.

Lagu I Knew You Were Trouble yang diciptakan Taylor Swift terinsipirasi dari mantan kekasihnya Harry Styles. Lagu ini menceritakan bagaimana Harry yang masih berusia 19 tahun saat itu menjadi terkenal dan dikelilingi banyak wanita tidak siap untuk menjalin hubungan yang serius dengan Taylor sementara Tayor saat itu berharap banyak kepada Harry (Reporter, 2013). Potongan lirik lagu ini "trouble... trouble... trouble..." menjelaskan bagaimana Harry membawa begitu banyak masalah dalam kehidupan Taylor (Woodward, 2017).

Saat membuat lagu Love Story, Taylor mengaku mendapatkan inspirasi dari kisah cinta Romeo \& Juliet. la mengaku menyukai cerita keduanya tetapi tidak dengan akhir kisah cinta mereka yang menyedihkan. Taylor merubah bagian akhir kisah Romeo \& Juliet menjadi bahagia dan menuliskannya dalam lirik lagu Love Story (Nelson, 2017). Saat diwawancarai oleh Time Magazine, Taylor pun menceritakan bahwa lagu ini ditulisnya untuk seseorang yang hampir ia kencani tetapi tidak jadi karena orang tua Taylor tidak menyukai pria tersebut (Maldonado, 2018). Lagu You Belong with Me dalam album Fearless merupakan ungkapan ketidakadilan yang dirasakan Taylor. Potongan lirik But she wears shorts skirts, I wear T-shirt menunjukan perbedaan bagai langit dan bumi antara taylor dan lawannya (Connell, 2017).

Tidak seperti yang banyak dibicarakan oleh publik, lagu Blank Space bukan ditulis Taylor untuk Harry Styles. Lagu ini bercerita mengenai seorang wanita yang terobesesi dengan kisah cintanya dengan mengencani banyak pria dan memanfaatkan para kekasihnya tersebut (Staff, 2017). Shake It Off merupakan salah satu single terlaris Taylor Swift yang terjual lebih dari 8 juta copy (Here are the 20 best-selling music stars online, 2016). Selain itu, salah satu 
lagu dari album 1989 ini juga menjadi on of the catchies song of the year dan menjuarai tangga lagu pop di berbagai chart lagu (Images, 2020).

Masalah Psikologis Dalam Play Victim. Seseorang yang melakukan Play Victim biasanya memiliki masalah emosional. Menurut Kate Martindale, Play Victim bisa menjadi masalah yang lebih dalam lagi seperti gangguan kepribadian (Personality Disorder). Pada akhirnya, semakin banyak perhatian yang kita habiskan dengan orang yang melakukan Play Victim, maka semakin banyak pula tenaga emosional yang terkuras. Hal tersebut tentunya akan melelahkan karena tidak ada hal yang membosankan seperti halnya melihat sebuah drama yang itu-itu saja (Martindale, 2016).

Mengatasi orang dengan perilaku play victim memang membutuhkan kesabaran lebih. Selain memberikan perhatian dan empati kita juga perlu melakukan beberapa hal lain seperti tidak menjuluki mereka sebagai "korban", membuat batasan dengan mereka sehingga pelaku play victim tidak dengan mudah membawa kita terjerumus ke dalam permainannya, memberikan bantuan dengan mengajak mereka berdiskusi atau berfikir sehingga mereka terlibat langsung di dalamnya dan berikan juga selalu mereka motivasi dan validasi sehingga kepercayaan diri mereka meningkat.

Dari pemahaman di atas, orang yang melakukan Play Victim memiliki masalah kepribadian bahwa ia senang untuk diperhatikan dan memnfaatkan seseorang atau kondisi tertentu untuk keuntungannya semata. Dalam hal ini, Tayor Swift yang melakukan Play Victim untuk mendapatkan keuntungan dan kesuksesan di hati para penggemarnya. Tidak dipungkiri wajah cantik dan tentunya lagu-lagunya yang menarik menjadi daya tarik Taylor Swift, tetapi apakah penggemarnya menyadari bahwa ada maksud yang dimainkan oleh Taylor Swift untuk mendapatkan hati penggemarnya? Jawaban dari pertanyaan tersebut dapat membantu peneliti menjelaskan tentang fenomena penelitian sehingga tujuan penelitian dapat tercapai.

Menyebarkan Gosip. Di elemen ini, peneliti mencoba melihat apakah para narasumber dapat mengidentifikasi elemen-elemen yang menunjukkan perilaku Taylor Swift yang memposisikan targetnya sebagai seorang "tersangka", dan kemudian menjelek-jelekkan reputasi dari targetnya tersebut, termasuk berita-berita bohong. Dari jawaban para narasumber, hampir semua sepakat, haters adalah salah satu "musuh" dan tersangka untuk Taylor Swift, yang membuat dirinya merasa sakit hati dan tertekan.

Selain haters, para mantan teman dekat pria Taylor Swift juga menjadi tersangka yang dapat membuat Taylor Swift menyebarkan gossip-gosip tentang mereka. Akan tetapi para narasumber merasa Taylor Swift tidak menjelek-jelekkan mereka terlalu berlebihan, hanya sekedar ungkapan perasaan yang masih dalam kategori wajar. Dan juga tidak menyebarkan berita-berita bohong yang mendiskreditkan para tersangka. Sehingga dari elemen ini dapat disimpulkan bahwa apa yang dilakukan Taylor Swift tidak berlebihan dan masih dalam taraf normal dari seorang wanita yang mencoba menyuarakan isi hatinya.

Sikap menyebarkan gosip tidak terlihat dari lirik-lirik lagu Taylor Swift juga memperlihatkan bahwa Taylor Swift mencoba menunjukkan refleksi wanita yang independen dan tidak terpengaruh oleh hal-hal yang bersifat negatif.

Memposisikan Diri sebagai Korban. Di elemen kedua ini, hampir semua narasumber juga setuju bahwa Taylor Swift memang menunjukkan bahwa ia adalah korban dari para tersangka dan musuh-musuhnya. Namun, terkait dengan elemen sebelumnya, para narasumber setuju, Taylor Swift hanya mencoba menyampaikan isi hatinya tanpa terlihat berlebihan dan juga tidak memiliki kecenderungan untuk mengganggu kredibilitas ataupun nama baik dari para mantan teman-teman dekatnya.

$\mathrm{Hal}$ ini terkait dengan asumsi pertama dari teori interaksi simbolik di mana dijelaskan 
bahwa makna berperan penting dan dibentuk oleh pengirim pesan dengan harapan bahwa penerima pesan dapat menangkap makna yang sama. Makna yang disampaikan Taylor Swift melalui lirik-lirik lagunya menegaskan bahwa Taylor Swift adalah korban dari hubunganhubungan asmaranya dan bagaimana para hatersnya juga memberi tekanan dapat ditangkap dengan baik oleh para penggemarnya dan mereka memberikan perasaan simpati terhadap apa yang dialami Taylor Swift.

Para penggemar juga menunjukkan simpati kepada Taylor Swift yang tetap berusaha menjaga sikapnya dengan tidak menunjukkan perilaku yang berlebihan dan negatif dalam menyampaikan perasaannya. Hal ini mungkin juga terkait dengan asumsi selanjutnya dari teori interaksi simbolik dimana konsep diri yang menjadi motivasi Taylor Swift muncul dalam lirik-lirik lagunya memang menjadi makna selanjutnya yang dicoba disampaikan oleh Taylor Swift untuk menunjukkan ia adalah seorang wanita yang positif, tegar dan tidak terpancing untuk membalas perlakukan negatif yang ia terima selama ini.

Terkait dengan asumsi terakhir, proses sosial dapat mempengaruhi hubungan individu dengan masyarakat bisa dibuktikan melalui pernyataan para narasumber, mendukung apa yang disampaikan Taylor Swift melalui lirik-lirik lagunya memang terkait dengan apa yang dirasakan oleh para penggemarnya, yang dalam kehidupan sehari-hari juga merasakan halhal yang dirasakan oleh Taylor Swift, sehingga kesamaan tersebut dapat menunjang keberhasilan Taylor Swift dalam membangun hubungan dengan para penggemarnya.

Mengintimidasi. Elemen selanjutnya yang ditanyakan adalah apakah para narasumber melihat ada kecenderungan Taylor Swift melakukan intimidasi terhadap lawan-lawannya. Sama seperti elemen sebelumnya, para narasumber yakin Taylor Swift tidak memiliki niat jahat untuk mengintimidasi ataupun mencelakakan para lawan-lawannya. Taylor Swift memang berusaha membuat orang percaya ia adalah korban, dan menjadi pihak yang tertekan dalam hubungan-hubungan yang terjadi dengan dirinya, akan tetapi ia tidak pernah mengancam atau membuat lawan-lawannya merasa tertekan.

Taylor Swift hanya memberikan sindiran-sindiran melalui lirik-lirik lagunya dan mencoba memberikan peringatan kepada para wanita lain untuk tidak merasakan perasaan yang ia rasakan, atau peringatan kepada para wanita lain untuk lebih berhati-hati dalam memilih pasangan.

Meminta Bantuan untuk Menghukum Tersangka. Berdasarkan jawaban para narasumber, elemen ini juga tidak terlihat jelas muncul dari lirik-lirik lagu Taylor Swift. Taylor Swift memang memiliki banyak teman dan penggemar. Akan tetapi apa yang ia harapkan dari para teman dan penggemarnya adalah dukungan yang bersifat positif untuk saling menguatkan. Para narasumber merasa persatuan dan keutuhan pertemanan yang diharapkan Taylor Swift jauh lebih penting dibandingkan perasaan untuk membalaskan sakit hati kepada para tersangka yang dirasakan sudah pernah menyakiti perasaan Taylor Swift.

Memantau Secara Diam-diam. Elemen terakhir ini juga menegaskan kembali jawaban dari para narasumber yang merasa Taylor Swift tidak punya niat jahat terhadap orang-orang yang telah menekan dan memperlakukannya dengan tidak adil. Melalui lirik-lirik lagunya Taylor Swift hanya memberikan isyarat ia tahu tentang perkembangan hubungan para mantan teman-teman dekatnya, tapi hanya sebatas tahu tentang informasi yang bersifat umum saja, karena Taylor Swift merasa tidak punya kepentingan lagi terhadap para mantannya tersebut.

Taylor Swift juga melalui lirik-lirik lagunya merasa tidak ada gunanya untuk mengetahui perbuatan atau tingkah laku para mantannya karena ia memiliki prediksi sendiri bahwa para mantannya tersebut punya kemungkinan besar untuk mengulangi kesalahan yang mereka 
sudah lakukan sebelumnya terhadap Taylor Swift. Untuk itu, terkait dengan elemen sebelumnya, Taylor Swift berkali-kali melalui lirik-lirik lagunya menyerukan persatuan para wanita untuk dapat mengatasi perlakuan yang tidak menyenangkan yang kemungkinan mereka dapatkan dari pasangan-pasangan prianya.

Di tiga elemen terakhir ini, tidak terlihat ada upaya menunjukkan perilaku playing victim oleh Taylor Swift melalui lirik lagunya. Hal ini akhirnya menunjukkan bahwa para penggemar Taylor Swift merasa bahwa Taylor Swift tidak secara kuat dan jelas melakukan perilaku playing victim. Terlepas dari apa yang terlihat, Taylor Swift memposisikan dirinya sebagai seorang korban, akan tetapi penempatan posisi korban tersebut masih dalam tahap yang wajar, karena dianggap sebagai ungkapan perasaan seorang wanita normal.

Selain itu, melalui lirik-lirik lagunya Taylor Swift tidak menunjukkan perilaku negatif yang bertujuan untuk membalas apa yang ia terima. Taylor Swift malah terkesan tidak peduli dan mengajak para wanita lain untuk tetap tegar dan menjadi wanita independen yang tidak tergantung terhadap pria serta dapat mengendalikan perasaannya.

\section{KESIMPULAN}

Dari hasil wawancara ke enam narasumber, dengan karateristik yang sudah dijelaskan sebelumnya, dapat ditarik kesimpulan yang menarik dari penelitian ini. Melalui lirik-lirik lagunya, Taylor Swift terlihat menyampaikan pesan bahwa ia adalah korban dan mengarah kepada perilaku playing victim, terutama dari hubungan-hubungan asmara yang sudah selesai dengan para mantan teman-teman dekat prianya, atau juga menjadi korban yang tertekan karena ejekan dan kritikan para haters-nya.

Ejekan dan kritikan yang disampaikan seperti Taylor Swift adalah contoh wanita yang tidak menghargai sebuah hubungan dan hanya memanfaatkan hubungan-hubungan tersebut untuk kesenangan dan kepentingan pribadi Taylor Swift. Akan tetapi Taylor Swift menyampaikan ia tidak terlalu peduli dengan perkataan orang atau lawannya. Karena ia merasa ia tidak dapat sepenuhnya mengatur pendapat dan perkataan orang lain.

Taylor Swift juga mencoba menyampaikan melalui lirik-lirik lagunya ia sudah mulai bosan dengan hal-hal yang melelahkan terkait dengan hubungan asmara. Taylor Swift lebih terbuka dengan perasaan dan tujuan dari hubungan yang ia harapkan. Sehingga ia bisa lepas dari kerumitan hubungan dan tidak menjadi korban dari hubungan-hubungan yang selanjutnya. Hal ini disampaikan dengan alasan Taylor Swift masih percaya bahwa hubungan asmara tetap bisa berhasil dan tidak skeptis walaupun dalam perjalannya ia memang banyak menemui hambatan dan cobaan terhadap hubungan-hubungannya.

Para penggemar Taylor Swift setuju apa yang disampaikan oleh Taylor Swift melalui liriklirik lagunya menunjukkan Taylor Swift adalah seorang korban. Akan tetapi menurut para narasumber, apa yang disampaikan Taylor Swift masih dalam batas kewajaran ungkapan perasaan seorang wanita. Taylor Swift hanya sebatas menyuarakan perasaannya yang terluka dan sama sekali tidak menunjukkan niat dan perbuatan jahat untuk membalas hal-hal negatif yang ia sudah terima sebelumnya. Hal ini dianggap sebagai sesuatu hal yang cukup berarti terkait dengan teori interaksi simbolik, tanggapan penggemar sebagai bagian dari masyarakat masih dapat melihat dan mempertahankan Taylor Swift sebagai idola mereka.

Kesamaan perasaan yang dapat muncul dari apa yang dirasakan para penggemarnya dan Taylor Swift memperkuat hubungan antara Taylor Swift dan para penggemarnya dan tetap membuat para penggemarnya loyal terhadap Taylor Swift. Hal ini juga dapat menunjukkan Taylor Swift sudah dianggap menyuarakan perasaan para penggemarnya, sehingga sekali lagi memperkuat hubungan antara Taylor Swift dan penggemarnya. 


\section{REFERENSI}

Apriliani, D. (2016). Ini Nih Katalog Mantan-Mantan Taylor Swift. Gimana Ya Rasanya Macarin Mereka Satu-Satu? Retrieved July 20, 2018, from https://www.hipwee.com/hiburan/ini-nih-katalog-mantan-mantan-taylor-swift gimana- ya-rasanya-macarin-mereka-satu-satu/

Reporter, B. D. M. (2013, February 19). Taylor Swift's I Knew You Were Trouble "100 percent" about Harry Styles. Retrieved from https://www.dailymail.co.uk/tvshowbiz/article-2280812/Taylor-Swifts-I-Knew-YouWere-Trouble-100-percent-Harry-Styles.html

Connell, A. (2017). The Definitive Timeline of Taylor Swift's 12-Year Professional Victim Act. Diakses dari http://www.revelist.com/celebrity/taylor-swift-victim/9198

Daymon, C., \& Holloway, I. (2011). Qualitative Research Methods in Public Relations And Marketing Communications. Routledge.

de Vries, M. F. K. (2014). Are You A Victim of The Victim Syndrome? In Mindful Leadership Coaching (pp. 68-86). Palgrave Macmillan UK.

healthpsychologyconsultancy. (2012, October 26). The Victim Personality. Retrieved from https://healthpsychologyconsultancy.wordpress.com/2012/10/26/the-victimpersonality/

Here Are The 20 Best-Selling Music Stars Online. (2016). Diakses dari http://www.businessinsider.sg/best-selling-music-artists-digital-era-2016$11 /$ ? $r=U S \& \mid R=T$

Images, P. A. H. (2020, February 28). Taylor Swift. Retrieved from https://www.biography.com/musician/taylor-swift

Maldonado, J. (2018, September 12). Taylor Swift's 'Love Story' Turns 10, And We're Feeling $\vee$ Nostalgic. Retrieved from https://www.j-14.com/posts/taylor-swift-lovestory-166148/

Martindale, K. (2016). What Does "Playing Victim" Mean? [Forum Post]. Diakses dari https://www.quora.com/What-does-\%E2\%80\%9Cplaying-victim\%E2\%80\%9D-mean

Nelson, M. (2017). Drama Chameleon: Won't the Real Taylor Swift Please Stand Up? Diakses dari https://www.stereogum.com/1960236/drama-chameleon-wont-thereal- taylor-swift-please-stand-up/franchises/sounding-board/

Operasi Playing Victim Pasca-Ahok Tersangka. Republika Online. (2017). Republika Online. Retrieved $29 \quad$ July 2017, from http://www.republika.co.id/berita/nasional/politik/16/11/17/ogrhtr385-operasiplaying- victim-pasca-ahok-tersangka

Raypole, C. (2019, December 12). How to Identify and Deal with a Victim Mentality. Retrieved from https://www.healthline.com/health/victim-mentality\#responding-toit

Romadhon, H. (2016). Taylor Swift, Sweetheart atau Serigala Berbulu Domba? Diakses dari https://www.kapanlagi.com/showbiz/hollywood/taylor-swift-sweetheart-atauserigala- berbulu-domba-7c5f53.html

Sakaw, P. (2017). Taktik Play Victim Mantan Presiden. KOMPASIANA. Retrieved 19 July 2017, from http://www.kompasiana.com/abahsakaw/taktik-play-victim-mantanpresiden_581a09bc5b7b61ec2a1e3fe0

Soraya. (2016). Taylor Swift: Dulu Sweetheart, Kini Penuh Sensasi \& Kontroversi. Diakses dari https://www.kapanlagi.com/foto/berita-foto/internasional/taylor-swift-dulu- 
sweetheart-kini-penuh-sensasi--kontroversi.html

Staff, B. (2017). Taylor Swift's 40 Biggest Billboard Hits. Diakses dari http://www.billboard.com/photos/7423130/taylor-swift-songs-best-hits-list

Staff, T. R. (2017). What Is Taylor Swift Doing? Diakses dari https://www.theringer.com/music/2017/8/23/16193036/taylor-swift-reputationanalysis

Swahn, A. L., \& Svahn, S. (2008). Creativity: A Science-based Outlook on Life and Work. AuthorHouse.

Vollert, R. (n.d.). Taylor Swift Lyrics. Diakses dari https://www.azlyrics.com/lyrics/taylorswift/shakeitoff.html

West, R. L., Turner, L. H., \& Zhao, G. (2018). Introducing Communication Theory: Analysis and Application (Vol. 2). New York, NY: McGraw-Hill.

Woodward, E. (2017). How Taylor Swift Played the Victim for A Decade and Made Her Entire Career. Diakses dari https://www.buzzfeed.com/elliewoodward/how-taylor-swiftplayed-the-victim-and-made-her-entire-caree?utm_term=.qhoygPJ3b\#.lkdWldzrk 